\title{
Kernos
}

Revue internationale et pluridisciplinaire de religion grecque antique

33 | 2020

Varia

\section{Du récit au rituel par la forme esthétique. Poèmes, images et pragmatique cultuelle en Grèce ancienne}

\author{
Julien Dechevez
}

\section{(2) OpenEdition}

\section{Journals}

Édition électronique

URL : https://journals.openedition.org/kernos/3498

DOI : 10.4000/kernos.3498

ISSN : 2034-7871

Éditeur

Centre international d'étude de la religion grecque antique

\section{Édition imprimée}

Date de publication : 31 décembre 2020

Pagination : 342-344

ISBN : 978-2-87562-264-8

ISSN : 0776-3824

Référence électronique

Julien Dechevez, « Du récit au rituel par la forme esthétique. Poèmes, images et pragmatique cultuelle en Grèce ancienne », Kernos [En ligne], 33 | 2020, mis en ligne le 31 décembre 2020, consulté le 06 décembre 2022. URL : http://journals.openedition.org/kernos/3498 ; DOI : https://doi.org/10.4000/ kernos.3498

Ce document a été généré automatiquement le 6 décembre 2022.

Tous droits réservés 


\title{
Du récit au rituel par la forme esthétique. Poèmes, images et pragmatique cultuelle en Grèce ancienne
}

\author{
Julien Dechevez
}

\section{RÉFÉRENCE}

Claude CALAME, Pierre elLINGER (dir.), Du récit au rituel par la forme esthétique. Poèmes, images et pragmatique cultuelle en Grèce ancienne, Paris, Les Belles Lettres, 2017. 1 vol. $15 \times 21,5 \mathrm{~cm}, 342$ p. ISBN : 978-2-251-44615-8.

1 Cet ouvrage collectif, qui rassemble onze contributions, est issu d'un colloque international organisé en 2012 et faisant suite à des ateliers de travail et des journées d'études, réalisés au sein du centre de recherche d'Anthropologie et d'Histoire des Mondes Anciens (AnHiMA). Le cadre de la réflexion est posé dès l'introduction par les deux responsables scientifiques de la publication, C. Calame et P. Ellinger. Les mythes grecs n'existent que dans la forme esthétique (poétique ou iconographique) qui les actualise, face à un public particulier et selon un contexte culturel déterminé. Dans cette optique est convoqué un vaste corpus littéraire, depuis les poètes épiques, fondateurs de la paideia grecque, jusqu'aux mythographes et sophistes de l'époque romaine qui retournent à la source de leur patrimoine culturel.

2 À travers l'étude du Péan VI de Pindare, qui reprend une version de la mort de Néoptolème, C.Calame décrypte le tissu de stratégies énonciatives de l'œuvre permettant de faire le lien entre le passé héroïque des protagonistes du récit et le présent de la performance rituelle lors des théoxénies de Delphes. La triple dynamique unissant le poème, le lieu de sa performance et le contexte dans lequel il s'inscrit se manifeste tout autant dans le Télèphe d'Archiloque, étudié par E. Bowie. La performance 
de ce long poème élégiaque devait, selon ce dernier, s'inscrire dans le cadre des cultes importants qu'Héraclès recevait sur l'île de Thasos, peut-être même au sein d'un temenos dédié au dieu. De manière similaire, L. Athanassaki étudie dans les Olympiques IV et $\mathrm{V}$ de Pindare l'actualisation du récit mythique à l'occasion de la célébration delphique d'un vainqueur aux jeux panhelléniques. L'A. insiste sur la fonction émotionnelle et sociopolitique suscitée par la performance rituelle, qui assure la bonne disposition du public envers celui qui est célébré. Dans une thématique similaire à celle abordée en ouverture par C. Calame, D. Bouvier examine ensuite dans la Néméenne VII les modalités d'adaptation de traditions narratives à un contexte rituel bien défini. L'A. démontre ainsi l'ambivalence de la figure du héros Néoptolème et la rhétorique subtile, oscillant entre blâme et éloge, que la narration de ses actions demandait.

P. Ellinger clôt l'étude des poètes lyriques en proposant une nouvelle lecture de la $\mathrm{XI}^{\mathrm{e}}$ Épinicie de Bacchylide. La clé d'interprétation de l'ode réside pour lui dans la juste compréhension de la figure d'Artémis invoquée sous l'épiclèse Agrotera. L'A. démontre par une confrontation du récit de Pindare avec les normes rituelles grecques que le spectre de prérogatives convoqué est bien plus large que les simples activités cynégétiques de la déesse : par la rage et la force qu'elle transmet, l'Artémis Agrotera est celle qui apporte finalement la victoire tant convoitée par Alexidamos à Delphes. L'ambivalence de la figure d'Artémis dans l'Iphigénie en Tauride constitue le cœur de l'étude menée par L. Bruit Zaidman. Artémis est présentée chez Euripide tantôt comme la sauveuse de l'héroïne, tantôt comme son bourreau. Outre une réflexion plus large sur le statut du sacrifice humain dans la Grèce ancienne, la tragédie contient une stratégie de conciliation qui se clôt sur l'apaisement des hommes et des dieux par la fondation de lieux de cultes et d'une prêtrise dédiés à Artémis en Attique. Dans sa contribution aussi limpide que riche en documentation, C. Brillante questionne le rapport entre l'identité faiblement structurée des Muses dans les traditions narratives et les cultes qui leur sont rendus, de préférence dans des espaces inhabités. En confrontant le témoignage d'Hésiode, celui de Pausanias et les données archéologiques, l'A. aboutit à la conclusion que le caractère marginal de ces figures supra-humaines est nécessaire à leur fonction de gardiennes de la parole poétique, car ce n'est que dans l'isolement que le poietēs peut aboutir, sous leur conduite, à la production d'un savoir nouveau.

4 F. Lissarrague choisit quant à lui de questionner les images, en partant du constat que les images «ne racontent pas, elles re-présentent, elles rendent présent» (p. 221). Sa contribution vise à démontrer, à partir des variations iconographiques du thème des armes de Thésée, la valeur proprement sémantique de l'image et, par l'activation d'un arrière-plan culturel qu'elle présuppose, sa fonction performative. D'une manière similaire, V. Pirenne-Delforge et G. Pironti prennent comme champ d'investigation un passage du sophiste Philostrate, où ce dernier décrit le tableau d'un chœur de jeunes filles dirigé par Sappho elle-même, en pleine récitation d'un hymne en l'honneur d'Aphrodite. L'évocation savante d'éléments relevant du domaine poétique, iconographique ou narratif constitue une stratégie d'actualisation de la présence divine, de façon similaire aux gestes posés par le chœur qui rappellent les traditions hésiodiques liées à la naissance d'Aphrodite. Un dernier détour par clément d'Alexandrie démontre comment l'héritage culturel grec subit une reconfiguration et une resémantisation au profit d'un tout autre système de pensée où le dieu est maintenant unique, exclusif et seul détenteur de l'alethēs logos. 
5 Les deux contributions finales de l'ouvrage s'intéressent à deux héros, Héraclès et Bellérophon. Entamant une démarche comparatiste, J. Bremmer évoque les divers rites de passage d'Héraclès relatés dans la Bibliothèque d'Apollodore. L'analyse de ce récit, aussi homogène qu'il puisse apparaître sous la plume de son auteur, révèle une démarche de compilation de la part du mythographe, qui harmonisa diverses traditions temporellement et spatialement éloignées relatives à ce héros dont toute la Grèce a contribué à forger le récit. Enfin, R. Woodard passe au crible d'une analyse structuraliste le mythe de Bellérophon. Convoquant la littérature irlandaise, védique ou encore égyptienne, l'A. souhaite mettre en exergue dans la légende du héros des caractéristiques relevant du prototype indo-européen de ce qu'il nomme le "guerrier dysfonctionnel» (p.316) pour ensuite montrer comment certains de ces éléments structurels, absents des traditions narratives, sont actualisés et matérialisés au sein d'un espace sacré tel que le Cranéion de Corinthe.

6 Appuyé sur des cas d'étude finement analysés et richement documentés, cet ouvrage souligne de manière significative la dimension pragmatique indubitablement conférée à ces traditions narratives. On pourra cependant regretter l'absence d'une partie conclusive confrontant les résultats parfois divergents auxquels les publications aboutissent et synthétisant les progrès méthodologiques obtenus. Ce livre ne manquera néanmoins pas de faire autorité pour quiconque décide de s'attaquer à l'épineuse question de la relation entre "mythe», «rite» et «culte» en contexte polythéiste grec.

\section{AUTEURS}

\section{JULIEN DECHEVEZ}

Université de Liège 